\title{
Isoform Specific Expression of the SDR-1 Protein, $\alpha$ and $\beta$ in Subregions of Adult Rodent Brain
}

\author{
Nelson D. Lopez', Ayae Kinoshita², Masafumi Taniwaki ${ }^{3}$, Hideaki Tada', Michio Shirozu', \\ Toru Nakano ${ }^{1}$, Kei Tashiro ${ }^{4}$ and Tasuku Honjol \\ ${ }^{\text {I} D e p a r t m e n t ~ o f ~ M e d i c a l ~ C h e m i s t r y, ~}{ }^{2}$ Department of Morphological Brain Science, Kyoto University Faculty of Medicine, Kyoto \\ 606-8507, Japan \\ ${ }^{3}$ Third Department of Internal Medicine, Kyoto Prefectural University of Medicine, Kyoto 602-0841, Japan \\ ${ }^{4}$ Center for Molecular Biology and Genetics, Kyoto University, Kyoto 606-8507, Japan \\ (Received 20 January 1999; and accepted 27 January 1999)
}

\begin{abstract}
Stromal cell-derived receptor-1 (SDR-1) $\alpha$ and $\beta$, also called gp55 and gp65, belong to the immunoglobulin (Ig) superfamily. Rabbit antisera specific to SDR-1 $\beta$ and those recognizing both $\alpha$ and $\beta$ forms of SDR-1 were raised to study regional distributions of SDR- $1 \alpha$ and $\beta$ in the adult rodent brain. Immunohistochemical studies of adult rat brains with either antibodies revealed a granular pattern of staining distributed within neuropils. SDR-1 $\beta$ form like immunoreactivity $(\beta-\mathrm{LI})$ was detected in limited regions, namely the glomerulus of the olfactory bulb and the superficial layers (layers II, III) of the cerebral cortex, whereas $\alpha \beta$-LI was found in the olfactory tubercle, cerebral contex, hippocampus, thalamus, midbrain, and molecular layer in the cerebellum, suggesting wider distribution of SDR-1 $\alpha$. The SDRI gene is highly conserved from Xenopus to human. The human SDR-1 cDNA was isolated and the human SDRl gene was mapped to chromosome $15 \mathrm{q} 22$ by fluorescence in situ hybridization.
\end{abstract}

A number of cell adhesion molecules of the Ig superfamily are involved in neurogenesis and maintenance of brain function, such as neuronal cell migration, neurite outgrowth, axonal fasciculation (4), axon guidance (17) and myelinization (20). Mutations of adhesion molecules of the Ig superfamily result in neurological diseases. For instance, mutations in the human L1 gene are associated with mental retardation and anomalous development of the nervous system (2). The human peripheral myelin PO protein gene is mutated in hereditary neuropathy (16). Down's syndrome cell adhesion molecule, whose gene has been mapped to human chromosome 21 , is con-

Correspondence to: Dr. Tasuku Honjo at the above address.

Tel: +81-75-753-4371; Fax: +81-75-753-4388

; E-mail: honjo@mfour.med.kyoto-u.ac.jp sidered to be involved in neural differentiation and development of the central and peripheral nervous system in Down's syndrome (19).

Stromal cell-derived receptor-1 (SDR-1), a type I transmembrane protein belonging to the $\mathrm{Ig}$ superfamily was previously isolated by our group using the signal sequence trap method $(11,14$, 15). Two isoforms of SDR-1, $\alpha$ and $\beta$, bearing two and three Ig domains, respectively, are generated by differential splicing. $\beta$ form contains a $\beta$ specific portion by a 116 -amino acid insertion in the extra-cellular region, while the rest of the protein is identical to the $\alpha$ form. SDR- $1 \alpha$ and $\beta$ turned out to be identical to the synaptic membrane glycoproteins gp55 and gp65, respectively (6). By biochemical fractionation studies, it was suggested that SDR-1 $\alpha /$ gp55 and SDR-1 $\beta$ / gp65 are enriched in synaptic membrane fraction $(3,18)$. By immunohistochemical study, the SDR- 
$1 \beta /$ gp65 protein was shown to localize in the processes and nerve termini of subsets of forebrain neurons (3), while the distribution pattern of SDR- $1 \alpha / \mathrm{gp} 55$ protein in the brain remained to be examined.

In this study, SDR- $1 \alpha$ and SDR- $1 \beta$ specific expression in adult rodent brain was examined to understand their functions by using two antibodies, each recognizing either SDR-1 $\beta$ specific region or the common region shared with $\alpha$ and $\beta$ forms of SDR- 1 . In addition, human counterparts of SDR- $1 \alpha$ and $\beta$ cDNA and genomic DNA were isolated and chromosomal localization of the $S D R l$ gene was mapped to study relationship between the $S D R 1$ gene and neuronal diseases.

\section{MATERIALS AND METHODS}

\section{Antibodies Against Either SDR-1-FC Fusion Protein or $\alpha \beta$-Specific Peptide}

The extra-cellular portion of the SDR-1 cDNA (nucleotide 1 through 663) (11) was fused with the $\mathrm{Fc}$ portion of the human $\mathrm{C} \gamma 1$ gene in pMKITNeo plasmid bearing the $\operatorname{SR} \alpha$ promoter (12). Stable transfectants of the mouse myeloma cell line X63 were selected in the presence of G418 (Sigma) at $1.0 \mathrm{mg} / \mathrm{mL}$. The fusion protein was purified to homogeneity from culture supernatants using a protein A-Sepharose column (Pharmacia). Antisera against the SDR-1-FC fusion protein (anti-SDR-l $\alpha / \beta$ ) were prepared in rabbits. A polypeptide consisting of 11 amino acids specific to the $\beta$ form (residues 59-69) was synthesized and used for antibody production (Biologica Co., Nagoya, Japan). Rabbit antibodies (anti-SDR- $1 \alpha / \beta$ and anti-SDR-1 $\beta$ ) were then affinity-purified by respective antigens.

\section{Western Blotting from the Adult Mouse Brain Tissue}

Brains from adult mice ( $8-12$ weeks) were dissected to yield cortex, olfactory bulb, striatum, hippocampus, cerebellum and midbrain plus pons. The whole brain and dissected tissues were homogenized in $100 \mathrm{mM} \mathrm{NaCl}, 10 \mathrm{mM}$ Tris- $\mathrm{HCl}$, and $1 \mathrm{mM}$ EDTA buffer ( $\mathrm{pH} 8.0$ ) and lysed by boiling in the sodium dodecyl sulfate (SDS) sample buffer $(2 \%$ SDS, $4 \%$ glycerol, $5 \% \quad \beta$ mercaptoethanol). The proteins were electrophorezed in polyacrylamide gels, electroblotted onto nitrocellulose membranes, probed with the anti-
SDR- $1 \alpha / \beta$ antibodies, or the anti-SDR $-1 \beta$ antibodies and visualized with ECL (Amersham) following the manufacturer's protocol.

\section{Immunohistochemistry of Adult Rat Brain}

Cryosections from adult male rats were prepared as described (5). The sections were immunostained with the affinity-purified anti-SDR $-1 \alpha / \beta$, or anti-SDR-1 $\beta$ antibodies; sections were incubated sequentially with (a) $1.0 \mu \mathrm{g} / \mathrm{mL}$ anti-SDR$1 \alpha / \beta$ or $1.0 \mu \mathrm{g} / \mathrm{mL}$ anti-SDR $-1 \beta$ antibodies in the presence of $5 \%$ goat serum, (b) $10 \mu \mathrm{g} / \mathrm{mL}$ goat biotinylated anti-rabbit IgG antibodies (Vector, Burlingame, CA), and (c) avidin-biotinylated peroxidase complex (ABC Standard, Vector; 1 : 100 dilution); all antibody solutions were diluted with $25 \mathrm{mM}$ phosphate-buffered saline containing $0.1 \%$ Triton $\mathrm{X}-100$. Bound peroxidase was visualized by incubation with $0.02 \%$ diaminobenzidine tetrahydrochloride, $0.04 \%$ nickel chloride and $0.003 \% \mathrm{H}_{2} \mathrm{O}_{2}$ in $50 \mathrm{mM}$ Tris- $\mathrm{HCl}(\mathrm{pH} 7.6)$. As controls, the primary antibodies were replaced by normal IgG, and no signal was detected. For adsorption test, the primary antibodies were preincubated with $10 \mu \mathrm{g} / \mathrm{mL}$ of the corresponding antigens overnight at $4^{\circ} \mathrm{C}$, and signals were erased.

\section{Genomic Southern Blot Analysis}

Essentially as described (10) with the following modifications. The membrane was probed with a $0.4 \mathrm{~kb} \beta$-specific cDNA fragment at $37^{\circ} \mathrm{C}$ instead of $32^{\circ} \mathrm{C}$ in the presence of $50 \%$ formamide.

\section{Isolation of the Human SDR-1 cDNA}

A human cDNA library from T98G human glioblastoma cell line (ATCC No CRL-1690) was screened with the mouse SDR- 1 cDNA as a probe (11). Nucleotide sequences of seven independent clones were determined on both strands by Dye Terminator Cycle Sequencing kit using Ampli Taq DNA polymerase (Applied Biosystems Inc.).

\section{Chromosomal in situ Hybridization (FISH)}

A genomic DNA library made in $\lambda$ DASH II phage (Stratagene, CA) was screened with human SDR-1 full length $(1.9 \mathrm{~kb}) \mathrm{cDNA}$. A $7 \mathrm{~kb}$ fragment of the $S D R l$ gene isolated was confirmed by nucleotide sequence determination, labeled with 
biotin-11-dUTP (Sigma, MO) by nick translation, and hybridized to metaphase chromosomes as described (13). The hybridization was detected with avidin-conjugated fluorescein isothiocyanate (Vector Laboratories, CA). Chromosomes were counterstained with $0.2 \mu \mathrm{g} / \mathrm{mL}$ of propidium iodine and $1 \mu \mathrm{g} / \mathrm{mL}$ of 4 , 6-diamidino 2phenylindole.

\section{RESULTS}

Immunoblot Analysis of SDR-1 $\alpha$ and $\beta$ in the Adult Mouse Brain

The specificities of the SDR-1 antibodies were checked with western blottings from cell lysates of $293 \mathrm{~T}$ cells transfected with sense and antisense cDNAs of SDR-1 $\alpha$ and $\beta$, and from mock transfected cells. The $\alpha$ form is detected by antiSDR I-Fc antibodies as a single band of $52 \mathrm{KDa}$ (data not shown). One single band of $68 \mathrm{KDa}$ corresponding to the $\beta$ form was detected using antipeptide antibody (Fig. 1A), as well as antiSDR1-Fc (Fig. 1B). No bands are detected in the lysate from mock transfected cells, nor from cells transfected with SDR-1 $\beta$ antisense (Fig. 1A and
B). The preimmune antisera did not give any specific signals, neither in western blot analysis, nor in immunohistochemical studies from the same cells (data not shown).

Whole brain homogenates from adult mice (812 weeks) contained two bands of 52 and $65 \mathrm{KDa}$ recognized by the anti-SDR- $1 \alpha / \beta$ antibodies (Fig. 1C lane 1 and D) and only one band of 65 $\mathrm{KDa}$ recognized by the $\beta$-specific antibodies (Fig. $1 \mathrm{C}$ lane 2 ), showing anti-SDR-1 $\beta$ does not cross react with SDR- $1 \alpha$ nor anyother proteins in the brain. The respective molecular weights of the SDR-1 isoforms are higher than those calculated from the amino acid sequences, probably due to glycosylation at five potential asparagine-linked glycosylation sites in the SDR- $1 \alpha$ and $\beta$ proteins $(3,7)$. The distribution profiles of the SDR- $1 \alpha$ and $\beta$ proteins in adult mouse brain was similar to that of adult rat brain (6), namely widespread but variable in various regions of the brain. As shown in Fig. ID, the $\beta$ form was not detected in cerebellum and midbrain including pons, while both forms were detected at approximately equal ratio in the cerebral cortex, hippocampus and striatum. In the olfactory bulb, the $\beta$ form protein

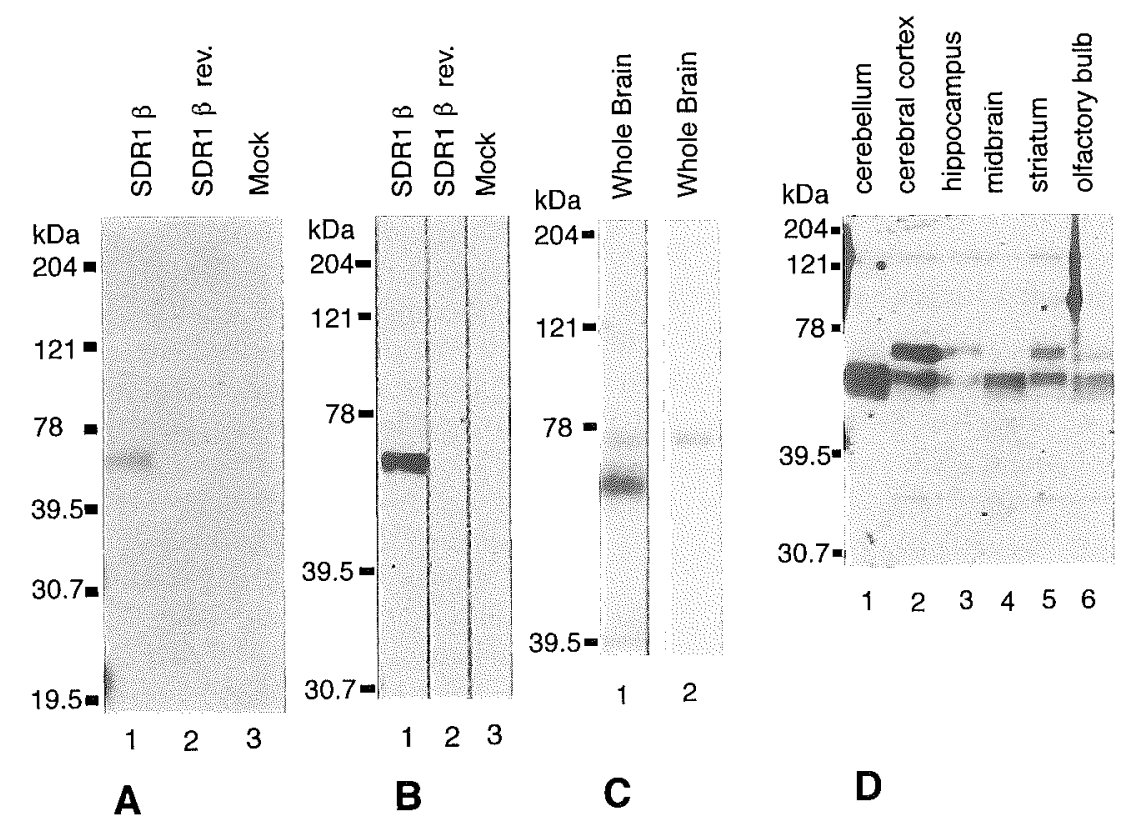

Fig. 1 Western analysis with polyclonal anti-SDR-1 $\alpha / \beta$ and anti-SDR-1 $\beta$ antibodies. A. 293T cell lysate form cells transfected with mSDR-1 $\beta$ (lane 1), SDR-1 $\beta$ in reverse direction (lane 2 ), and mock transfected (lane 3) were resolved by electrophoresis, transferred to nitrocellulose and probed with anti-SDR-1 $\beta$ antibodies. B. Lanes 1, 2 and 3 are as in panel A. The membrane was probed with anti-SDR-1 $\alpha / \beta$ antibody (lane 1) and anti-SDR-1 $\beta$ antibody (lane 2). $C$, Whole mouse adult brain homogenate was probed with anti-SDR$1 \alpha / \beta$ antibodies (lane 1) and anti-SDR-1 $\beta$ antibodies (lane 2). D, Regional distribution of mSDR-1 $\alpha$ and $\beta$ in the adult mouse brain. Extracts from each parts of the brain were probed with anti-SDR $1 \alpha / \beta$ antibodies. 
represents approximately one fifth of the total SDR-1 proteins. In the cerebral cortex the $\beta$ form is more abundant than the $\alpha$ form. These distribution profiles are in general agreement with rat SDR-1 distribution pattern (3).

Regional Distribution of the SDR-1 $\alpha$ and $\beta$ proteins in the Brain by Immunohistochemistry

Although SDR-1 $\alpha / \beta$ like immunoreactivity $(\alpha \beta-\mathrm{LI})$ was distributed in diverse CNS regions, $\beta$-LI was found only in limited regions. $\alpha \beta$-LI was specially marked in the olfactory tubercle (Fig. 2A) and cerebral cortex (Fig. 2B), wherein the superficial layers of the cerebral cortex were more intensely labeled than the deeper layers. The caudate-putamen was moderately immunolabeled (Fig. 2B). In the hippocampus, $\alpha \beta$-LI was found in the dentate gyrus and CAl-CA4 (Fig. 2C), the striatum oriens of $\mathrm{CA} 3$ being most strongly labeled. Some thalamic subnuclei including the lateral and medial geniculate nuclei were moderately labeled (Fig. 2C, D). In the midbrain, SDR1 is expressed in the pars reticulata of the substantia nigra and the interpeduncular nucleus (Fig. 2D). $\alpha \beta$-LI was intense in the molecular layer of the cerebellar cortex, but not in the Purkinje or granular layers (Fig. 2E). On the other hand, $\beta$-LI was found only in limited regions. They were distributed in the glomerulus of the olfactory bulb (Fig. 3A) and the superficial layers (layers II, III) of the cerebral cortex (Fig. $3 \mathrm{~B})$. And $\beta$-LI was virtually absent from thalamus, hypothalamus, midbrain, hippocampus, striatum, cerebellum, pons, and medulla oblongata. Under the light microscopy, the areas immunostained for either $\alpha \beta$ or $\beta$-LI displayed granular appearance (Fig. $2 \mathrm{~F}$ and data not shown). Small granules showing $\alpha \beta$ or $\beta$-LI were distributed in neuropil, but not within neuronal profiles.

Cloning and Characterization of the Human SDR-1 $\alpha$ and $\beta$ cDNAs and Chromosomal Mapping of the Human SDR1 Gene

We analyzed the evolutional conservation of the SDRl gene by Southern hybridization using mouse SDR-1 cDNA as a probe. As shown in Fig. 4A, crosshybridization bands with the mouse SDR 1 gene were found in Xenopus laevis, rabbit, mouse and human, but not in Drosophila melanogaster. Southern blots performed on dif-

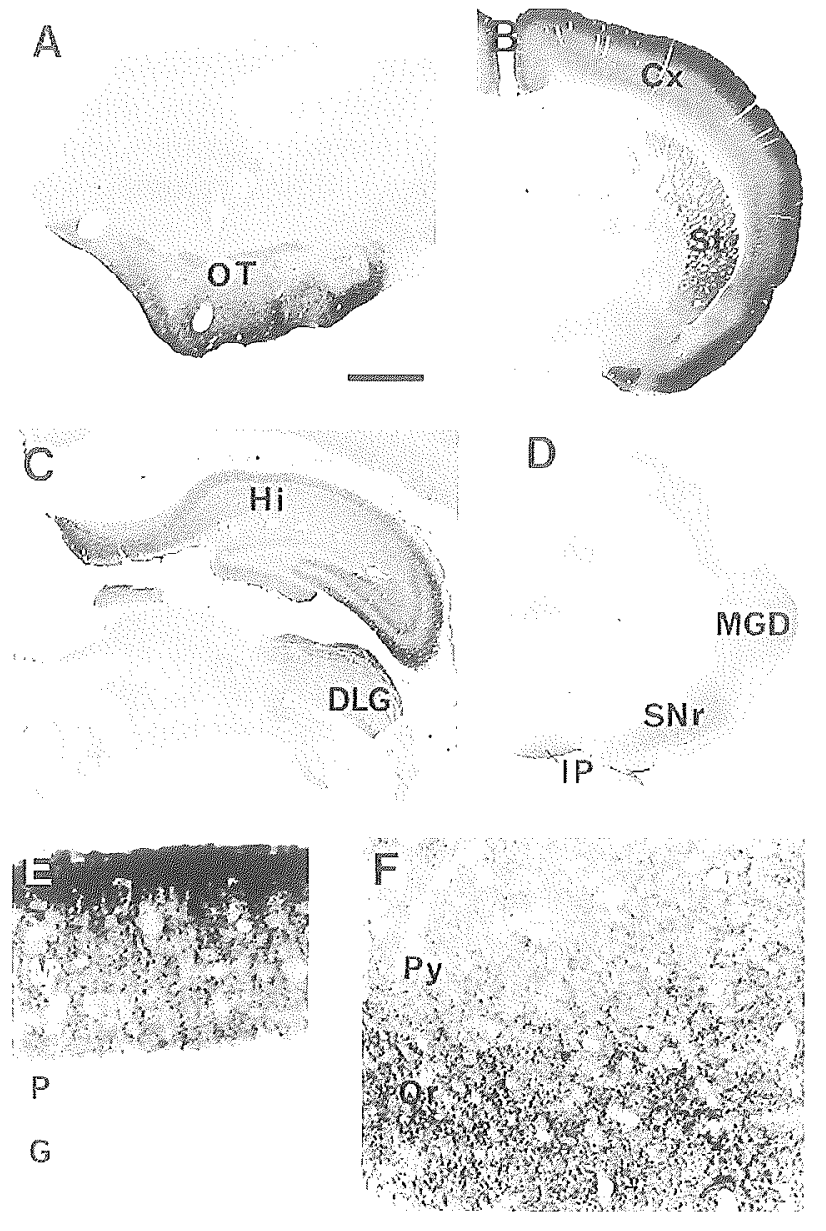

Fig. 2 Photomicrographs of the $\alpha \beta$-LI in the rat frontal sections. A, Neuropil of the olfactory tubercle (OT) shows $\alpha \beta$-LI. B, The cerebral cortex $(\mathrm{Cx})$ and neostriatum (St) shows $\alpha \beta-\mathrm{LI} . \quad \mathrm{C}$, In the hippocampus (Hi), $\alpha \beta$-LI is distributed in the neuropil. The dorsal part of the lateral geniculate nucleus (DLG) is also moderately immunolabeled. D, The neuropil in the dorsal part of the medial geniculate nucleus, the pars reticulata of the substantia nigra and the interpeduncular nucleus show $\alpha \beta$-LI in the midbrain. E, The molecular layer (M) of the cerebellar cortex is markedly stained, while the Purkinje layer $(P)$ or granule layer $(G)$ is devoid of the immunoreactivity. F, Higher power magnification of the $\alpha \beta$-LI in the CA3 region in the hippocampus. Small granules showing $\alpha \beta$-LI are distributed densely in the neuropil of the stratum oriens (Or). Py, pyramidal cell layer. Scale bars; $0.5 \mathrm{~mm}$ for A, $2 \mathrm{~mm}$ for $\mathrm{B}, 1 \mathrm{~mm}$ for $\mathrm{C}$ and $\mathrm{D}, 40 \mu \mathrm{m}$ for $\mathrm{E}$ and $67 \mu \mathrm{m}$ for F.

ferent restriction analysis suggest a single copy of the SDRI gene in the mouse genome (data not shown). 


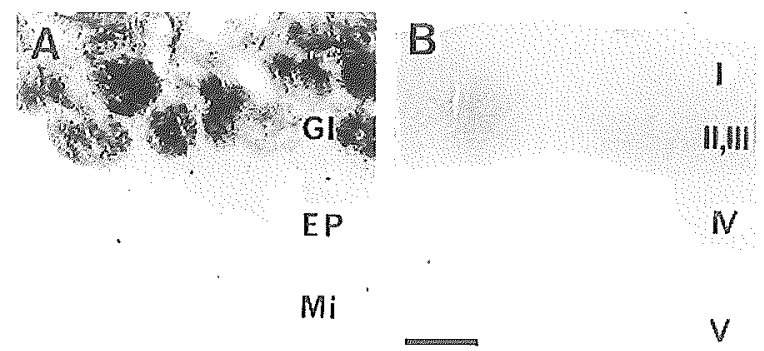

Fig. 3 Photomicrographs of the $\beta$-LI in the rat frontal sections. A, Intense $\beta$-like granular staining is observed in the glomerulus of the olfactory bulb (Gl). EP, external plexiform layer; Mi, mitral cell layer. B, The neuropil of the superficial layers (layers II and III) of the cerebral cortex shows moderate immunoreactivity for $\beta$. Scale bars; $0.16 \mathrm{~mm}$ for $A$ and $0.33 \mathrm{~mm}$ for $B$.

We isolated and characterized the human SDR1 cDNAs and genomic DNA. Sequence comparison between the human and mouse SDR-1 protein revealed $94 \%$ identity at the amino acid sequence level. In addition, a 12-bp insertion in the cytoplasmic portion was detected in 1 of 7 independent $\alpha$ clones analyzed, like rat cDNA analysis (6). Northern blot analysis using human SDR-1 $\alpha$ probe revealed a ubiquitous expression patter of the human SDRI gene in different human organs (Fig. 4B). This expression pattern is consistent with that observed in mouse (data not shown) and rat (6) tissues.

The SDRI gene was mapped to human chromosome 15 by fluorescence in situ hybridization using a 7-kb genomic fragment containing the SDR-1 gene as a probe. Of 20 metaphase cells examined, 19 showed the specific hybridization in the long arm of chromosome 15 (15q22). A search in the On-line Mendelian Inheritance in Man database has revealed that two diseases, BardetBiedl syndrome type 4 and variant late infantile neuronal ceroid lipofuscinosis, whose symptoms include mental retardation, retinal or cerebellar involvement have been linked to chromosome $15 q 22-q 23(1,9)$. To study the function of SDR-1, the gene targeting study is in progress.

\section{DISCUSSION}

In this study, we showed the localization of SDR $-1 \alpha / \beta$ and SDR $-1 \beta$ proteins in the adult brain of rats. Although regional distribution of the SDR-1 $\beta$ protein in the brain and in situ hybridization data of $\alpha$ and $\beta$ have been reported
$(6,3)$, regional distribution of SDR-1 $\alpha$ was not yet reported. Since the distribution pattern of the SDR-1 $\alpha$ protein could be different from that of its mRNA, immunohistochemical studies with anti-SDR- $1 \alpha / \beta$ and anti-SDR-1 $\beta$ antibobies were carried out on adult rat brain. As there are no SDR-1 $\alpha$ specific protein portion, SDR- $1 \alpha$ expression has to be deduced by subtracting the SDR $-1 \beta$ expression region from the SDR $-1 \alpha / \beta$ positive regions. In conclusion, SDR-1 $\alpha$ distribution was deduced to be in olfactory tubercle, cerebral cortex, caudate-putamen, the dentate gyrus and CAl-CA4 in the hippocampus, the lateral and medial geniculate nuclei in the thalamus, the pars reticulata of the substantia nigra, the interpeduncular nucleus in the midbrain and the molecular layer of the cerebellar cortex. The spatial resolution of in situ hybridization in the former study (6) was not so high and the result was described very roughly as "almost homogeneous labeling throughout the brain" (6). Our immunohistochemical study is the first precise description on SDR-1 $\alpha$ distribution in the adult rat brain. SDR- $1 \alpha$ protein has distinct sublocalizations in the brain.

Other new finding in our study is the SDR- $1 \beta$ protein expression in the glomerulus of the olfactory bulb (Fig. 3A), suggested by biochemical data (Fig. 1D) and in situ hybridization study (6, 3 ), was confirmed immunohistochemically. Also, we detected more SDR- $1 \beta$ protein in the superficial layers (layers II, III) of the cerebral cortex (Fig. 3B) than other layers, while more distribution in the layer I and layers IV-VI were described in the former study (3). Although, both mRNA and protein of SDR-1 $\beta / \mathrm{gp} 65$ were reported to be positive in striatum and hippocampus in the former studies $(6,3)$, we could not detect the SDR-1 $\beta$ protein in these regions by our immunochemical study (Fig. 3 and data not shown). Specificities of the antibodies used in this study were shown in Fig. 1 and those are similar to the antibodies used in the former studies $(6,3)$. Our anti-SDR- 1 antibodies is really SDR- $1 \beta$ specific as shown in (Fig. 1C lane 2), while the antibodies used in the former study (3) recognized both SDR $-1 \alpha$ and $\beta$ in the Western analysis and were discussed to be unable to detect SDR-1 $\alpha$ in immunohistochemistry. So, we do not know what reasons gave the difference between our immunohistochemical data and former ones at this moment, it can be because of the difference in the specificity of the antibodies used. 


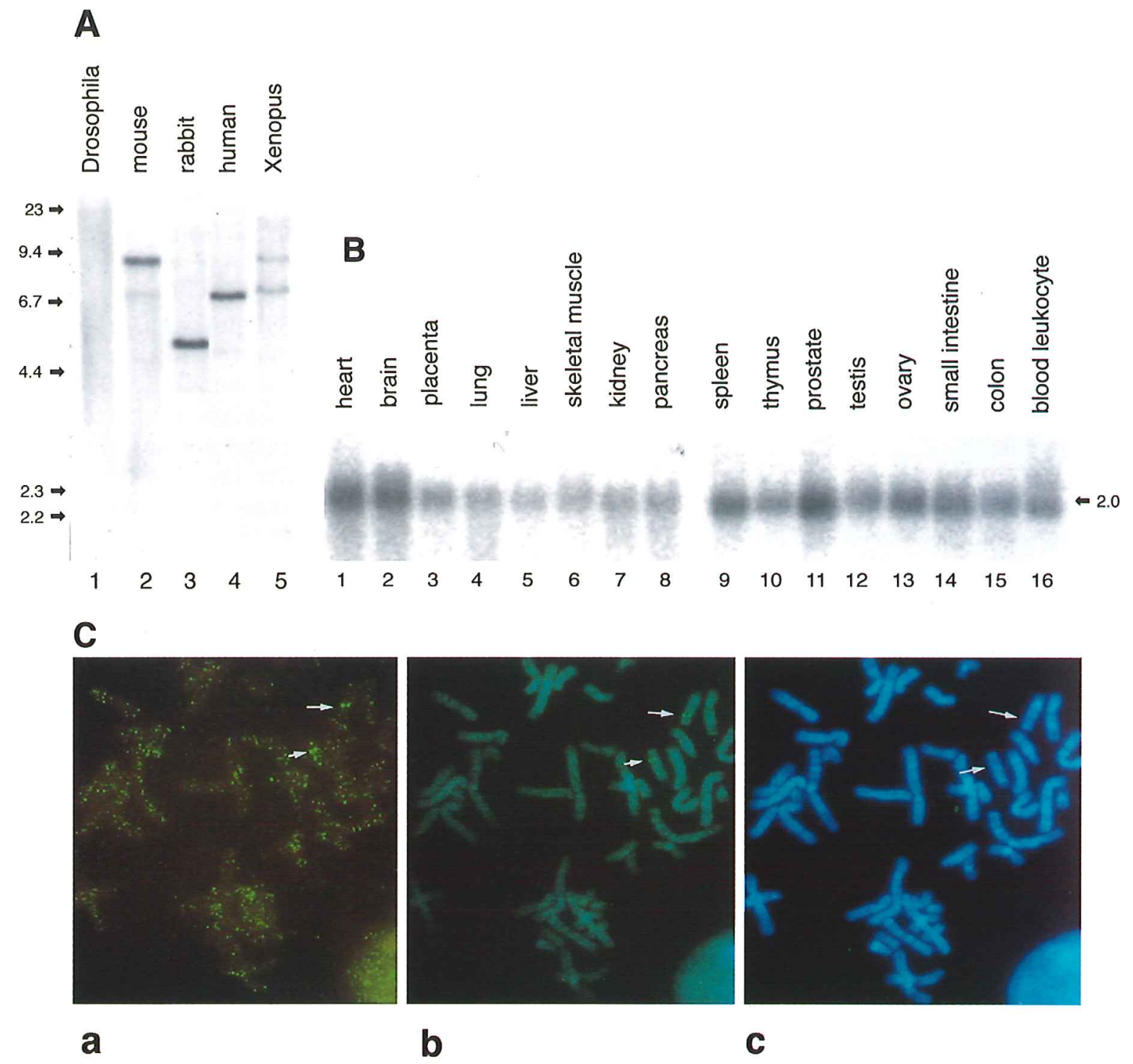

Fig. 4 Characterization of the SDRI gene. A, Genomic Southern blot analysis. B, Northern hybridization of human organo-blots with the human SDR-1 $\alpha$ full length cDNA probe. C, Chromosomal localization of human SDR1 gene by fluorescence in situ hibridization (FISH). a, The position of SDRl gene is indicated by arrow. b, The picture "a" was superimposed to "c". c, The Q-band pattern of the same metaphase showing the hybridization signal localized to chromosome $15 \mathrm{q} 22$.

SDR-1 may be involved in cell-cell interactions or cell-substrate interactions because it belongs to the immunoglobulin super family. Since the intracellular region of SDR-1 consists of only 40 amino acid residues and does not bear any known motifs, it is difficult to speculate any further possibilities of its function. As gene targeted mice of basigin/neurothelin, which is the most homologous to SDR-1 among the immunoglobulin super family members, suggested its important role in memory, as well as in the sensory function (8). Gene targeting of the SDR-1 gene will give important hint to reveal its function.

The other important approach to elucidate the function of SDR-1 is to find hereditary diseases associated with the chromosomal locus of the SDR-1 gene. Indeed, two hereditary neural diseases were mapped to $15 \mathrm{q} 22$ and polymorphic linkage of the SDR-1 gene is being studied in 
these genetic disease patients.

\section{Acknowledgments}

We would like to thank Dr. K. Maruyama for kind gift of pMKITNeo. We thank Dr. S. Toyokuni, Department of pathology, Dr. M. Kinoshita, Department of Molecular Oncology, Drs. A. Morrison and K. Tanigaki, Department of Medical Chemistry, Kyoto University Faculty of medicine for intellectual contribution to this work. We thank Ms. N. Tomikawa and Ms. M. TANAKA for technical assistance. The nucleotide sequences reported in this paper have been submitted to the GenBank/EMBL/DDBJ databases with the accession numbers AF109126 and AF 109127 for human SDR-1 $\beta$ and $\alpha$ cDNA, respectively.

\section{REFERENCES}

1. Bruford Ea, Riste R, Teague Pw, Porter K, Thomson Kl, Moore At, Jay M, Warburg M, Schinzel A, Tommerup N, Tornqvist $\mathrm{K}$, Rosenberg T, Patton M, MANSFIELD DC and WRIGHT AF (1997) Linkage mapping in 29 Bardet-Biedl syndrome families confirms loci in chromosomal regions $11 \mathrm{q} 13,15 \mathrm{q} 22.3-\mathrm{q} 23$, and $16 \mathrm{q} 21$. Genomics 41, 93-99.

2. Dahme M, Bartsch U, Martini R, Anliker B, SCHACHNER $M$ and MANTEi $N$ (1997) Disruption of the mouse Ll gene leads to malformations of the nervous system. Nature Genet. 17, 346-349.

3. Hill Ie, Selkirk Cp, Hawkes Rb and Beesley Pw (1988) Characterization of novel glycoprotein components of synaptic membranes and postsynaptic densities, gp65 and gp55, with a monoclonal antibody. Brain Res. 461, 27-43.

4. Kamiguchi H and Lemmon V (1997) Neural cell adhesion molecule L1: signaling pathways and growth cone motility. J. Neurosci. Res, 49, 1-8.

5. Kinoshita A, Ohishl H, Nomura S, Shigemoto R, Nakanishi $S$ and Mizuno N (1996) Presynaptic localization of a metabotropic glutamate receptor, mGluR4a, in the cerebellar cortex: a light and electron microscope study in the rat. Neurosci. Lett. 207, 199-202.

6. Langnaese K, Beesley Pw and Gundelfinger Ed (1997) Synaptic Membrane Glycoproteins gp65 and gp55 Are New Members of the Immunoglobulin Superfamily. $J$. Biol. Chem. 272, 82I-827.

7. Langnaese K, Mummery $R$, Gundelfinger Ed and BEESLEY PW (1998) Immunoglobulin superfamily members gp65 and gp55: tissue distribution of glycoforms. FEBS Lett. 429, 284-288.

8. Naruhashi K, Kadomatsu K, Igaklura T, Fan Qw, Kuno
N, Muramatsu H, Miyauchi T, Hasegawa T, Itoh A, Muramatsu $T$ and Nabeshima $T$ (1997) Abnormalities of sensory and memory functions in mice lacking Bsg gene. Biochem. Biophys. Res. Commun. 236, 733-737.

9. Sharp Jd, Wheeler Rd, Lake Bd, Savukoski M, Jarvela Ie, Peltonen L, Gardiner Rm and Williams Re (1997) Loci for classical and a variant late infantile neuronal ceroid lipofuscinosis map to chromosomes $11 \mathrm{pl} 15$ and 15q21-23. Hum. Molec. Genet. 6, 591-595.

10. Shirozu M, Nakano T, Inazaina J, Tashiro K, Tada H, Shinohara $T$ and Honjo $T$ (1995) Structure and chromosomal localization of the human stromal cellderived factorl (SDF1) gene. Genomics 28, 495-500.

11. Shirozu M, Tada H, Tashiro K, Nakamura T, Lopez Nd, Nazarea M, Hamada T, Sato T, Nakano $T$ and Honjo $T$ (1996) Characterization of Novel Secreted and Membrane Proteins Isolated by the Signal Sequence Trap Method. Genonics 37, 273-280.

12. Takebe Y, Seiki M, Fujisaiva J, Hoy P, Yokota K, Aral K, YoshidA M and ARAI N (1988) SR alpha promoter: an efficient and versatile mammalian cDNA expression system composed of the simian virus 40 early promoter and the R-U5 segment of human T-cell leukemia virus type 1 long terminal repeat. Mol. Cell. Biol. 8, 466-72.

13. Taniwaki M, Matsuda F, Jauch A, Nishida K, Takashima T, Tagawa S, Suglyama H, Misawa $S$, Abe T and Kashima K (1994) Detection of 14q32 Translocations in B-Cell Malignancies by In Situ Hybridization With Yeast Artificial Chromosome Clones Containing the Human IgH Gene Locus. Blood 83, 2962-2969.

14. Tashiro K, Tada H, Heilker R, Shirozu M, Nakano T and Honjo $T$ (1993) Signal sequence trap: a cloning strategy for secreted proteins and type I membrane proteins. Science 261, 600-603.

15. Tashiro, K., Nakano, T. and Honjo, T. (1997) Signal sequence trap. Expression cloning method for secreted proteins and type 1 membrane proteins. Methods. Mol. Biol. 69, 203-219.

16. Uyemura K, Asou H, Yazaki T and Takeda Y (1996) Cell-adhesion proteins of the immunoglobulin superfamily in the nervous system. Essays Biochem. 31, 37-48

17. Volenec A, Bhogal Rk, Moorman JM, Leslie Ra and Flanigan TP (1997) Differential expression of DCC mRNA in adult rat forebrain. Nelloreport 8, 2913-2917.

18. Willmott T, Skitsa I, Hill I, Mummery R and Beesley Pw (1992) Molecular characterisation and structural relationship of the synapse- enriched glycoproteins gp65 and gp55. J. Neurochem. 58, 2037-2043.

19. Yamakaivat K Hudt Yk, Haendelt Ma, Hubert R, Chen Xn, Lyons Ge and Korenberg JR (1998) DSCAM: a novel member of the immunoglobulin superfamily maps in a down syndrome region and is involved in the development of the nervous system. Hum. Mol. Genet. 7, 227-237.

20. Yazaki T, Miura M, Asou H, Toya $S$ and Uyemura $K$ (1994) Peripheral myelin PO protein mediates neurite outgrowth of cortical neurons in vitro and axonal regeneration in vivo. Neurosci. Lett. 176, 13-16. 